\title{
A SYNTHESIZED AHP-SPEARMAN MODEL FOR MENSURATION THE SEGREGATION OF PREFERENCES FOR PUBLIC TRANSPORT SYSTEM ENHANCEMENT
}

\author{
SARBAST MOSLEM, SZABOLCS DULEBA
}

\begin{abstract}
Latterly, a superior utilization of public transport can be a remedy to mitigate the traffic especially in big cities, thereby, to environmental, economic and public health problems. However, the alternatives for reclamation are myriad and in spite of this consensus of necessity, reclamation decisions are often censured by the public. Predominantly, a significant difference can be detected between planners' and passengers' notion about amelioration matter. The aim of this paper is to enumerate public demand for public bus transport improvement, by analyzing public bus transport supply quality criteria between planners and public in Mersin City, Turkey. As a methodology, a combined Analytic Hierarchy Process (AHP) and Spearman correlation technique have been applied in order to illuminate the chasms between planners and public.
\end{abstract}

\section{INTRODUCTION}

The population growth and rapid urbanization in all cities makes public transport system the right solution to reduce traffic, environmental and public health problems. However, passenger participation in decision making is a critical issue, where they can participate in decisions related to their daily life. This will make a kind of motivation for passengers and could lead to attract non passengers [1, 2]. In USA citizens participate in transportation strategies and development project decisions directly through the law called Safe, Accountable, Flexible, Efficient Transportation Equity Act a Legacy for Users (SAFETEA-LU) [3], it was signed into law by president George W. Bush on August 10, 2005 . Also in the EU citizens participate in decision making indirectly through the creation process of Sustainable Urban Mobility Plan (SUMP).

The aim of this study paper is to evaluate public demand for public bus transport improvement, by analyzing public bus transport supply quality

Date: Review January 2, 2018, accepted January 22, 2019.

Keywords: Analytic Hierarchy Process (AHP); Spearman's rank correlation coefficient; public transport; multi criteria decision making (MCDM); supply quality 
criteria between planners and public in Mersin City, Turkey, and compare between different groups. Consequently, transport system planners have been started using MCDM applications for solving the problems and improving public transport projects [4,5]. However, to illustrate the chasms between planners and public a combined AHP approach and Spearman correlation technique have been applied as a methodology. As clearly attested to in the recent study, AHP is a well-proven MCDM method and it has been widely discussed and used since its official appearance [6-8]. AHP is a subjective and consistent method and is considered as expert evaluation, thus involving a large sample in the analysis is not important [9] and statistical representatively criterion cannot be claimed.

\section{METHODOLOGY}

This paper aims to rate the most important factors related to public bus transport system supply quality and find out the differences of preferences between passenger and planner groups. A Synthesized AHP-Spearman Model has been selected as a methodology to analyze the data.

In order to detect what passengers expect from public transport supply quality. Once we found out the desired quality, ranking the factors may give the decision makers the real passenger demand and help improve future public transport planning. The concept of "Supply Quality" for public transport had been clarified by Duleba [2], where he constructed the AHP model in order to evaluate dynamically a Japanese city's (Yurihonjo) bus transportation system

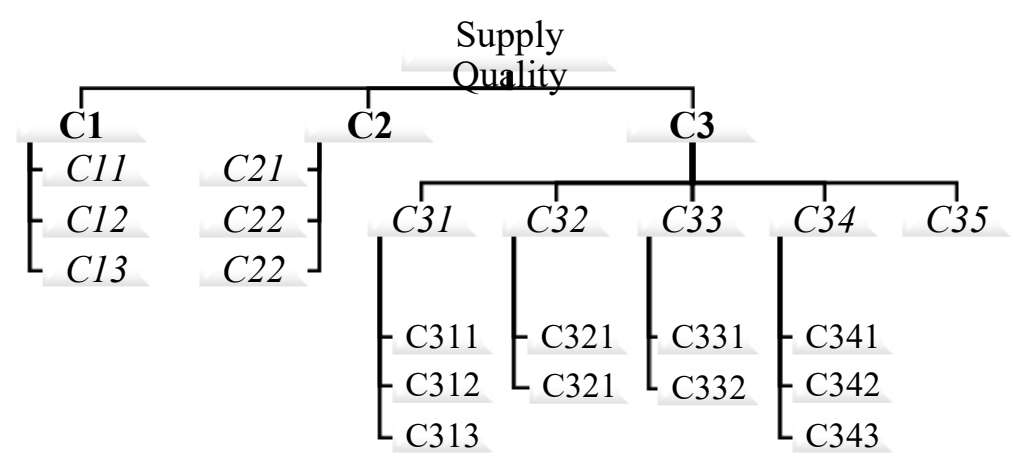

Figure 1. The hierarchical structure of public bus transport [2]

In the hierarchal model for public transport supply quality three levels have been constructed. However, the three levels encapsulate twenty four criteria, the first level includes three main criteria $\mathrm{C} 1, \mathrm{C} 2$ and $\mathrm{C} 3$, the second level includes eleven sub criteria C11, C12 and C13 as sub criteria for C1 and C21, C22 and C23 as sub criteria for C2 and C31, C32, C33, C34 and C35 as sub criteria for $\mathrm{C} 3$, however, the third level encapsulate ten specific sub criteria related to the previous level, as presented in Figure 1. A brief definition for all criteria have been defined in Table 1.

Table 1. Public bus transport supply quality criteria 


\begin{tabular}{ll}
\hline Criteria & Explanation \\
\hline C1 & $\begin{array}{l}\text { "Service Quality", everything excluding } \\
\text { transport it self } \\
\text { "Transport Quality", for real time on vehicle }\end{array}$ \\
"Tractability", getting information from every \\
aspect
\end{tabular}

Based on the hierarchy, pairwise comparison matrices (PCM) have to be created. It is an assumption of the AHP that people can better decide between two issues at a time than solving a more complex decision among 
more factors. The hierarchy constitutes groups within elements of the complex decision following the branches, thus pairwise comparisons can be created by comparing the factors that belong to the same branch.

In the recent case, one $3 \times 3$ PCM has been created for the first level, one $5 \times 5$ and two $3 \times 3$ PCMs for the second level and two $3 \times 3$ and two $2 \times 2$ matrices for the third level. For the first level the following questions have been asked: 'Compare the importance of improvement for the service quality and transport quality elements. Compare the importance of improvement for the service quality and tractability elements. Compare the importance of improvement for the transport quality and tractability elements.' For the second, and third level the same procedure has been followed. AHP utilizes the special characteristics of pairwise comparison matrices. A theoretical PCM is quadratic, reciprocal and consistent.

The matrix A is considered consistent if all of its elements are positive, transitive and reciprocal as

$$
\begin{aligned}
& a_{i k}=a_{i j} \cdot a_{j k}, \\
& a_{i j}=1 / a_{j i}
\end{aligned} .
$$

The dominant eigenvector of such PCM is trivial to be determined by Saaty's eigenvector method [10]. If $\mathrm{A}$ is a consistent matrix, then the eigenvector $\mathrm{w}$ can be calculated as, where is the maximum eigenvalue of the matrix A.

Although in AHP, decision makers most likely do not evaluate PCM-s consistently (for the evaluation, the Saaty scale is recommended, see Table 2.) the eigenvector method can be used provided consistency check has been conducted for the evaluations.

Table 2. Judgment scale of relative importance for pairwise comparisons

$$
\text { (Saaty's 1-9 scale) }
$$

\begin{tabular}{|c|l|l|}
\hline $\begin{array}{c}\text { Numerical } \\
\text { values }\end{array}$ & Verbal scale & Explanation \\
\hline 1 & $\begin{array}{l}\text { Equal importance of both } \\
\text { elements }\end{array}$ & $\begin{array}{l}\text { Two elements contribute } \\
\text { equally }\end{array}$ \\
\hline 3 & $\begin{array}{l}\text { Moderate importance of one } \\
\text { element over another }\end{array}$ & $\begin{array}{l}\text { Experience and judgment } \\
\text { favour one element over } \\
\text { another }\end{array}$ \\
\hline 5 & $\begin{array}{l}\text { Strong importance of one } \\
\text { element over another }\end{array}$ & $\begin{array}{l}\text { An element is strongly } \\
\text { favoured }\end{array}$ \\
\hline 7 & $\begin{array}{l}\text { Very strong importance of one } \\
\text { element over another }\end{array}$ & $\begin{array}{l}\text { An element is very } \\
\text { strongly dominant }\end{array}$ \\
\hline 9 & $\begin{array}{l}\text { Extreme importance of one } \\
\text { element over another }\end{array}$ & $\begin{array}{l}\text { An element is favoured by } \\
\text { least an order of } \\
\text { magnitude }\end{array}$ \\
\hline
\end{tabular}




\begin{tabular}{|c|l|l|}
\hline $2,4,6,8$ & Intermediate values & $\begin{array}{l}\text { Used to compromise } \\
\text { between two judgments }\end{array}$ \\
\hline
\end{tabular}

Consequently, during the AHP process the consistency of answers must be examined by Saaty's Consistency Index $(C I)$ and Consistency Ratio $(C R)$ $[11,12]$ :

$$
C I=\frac{\lambda_{\max }-n}{n-1},
$$

where $C I$ is the consistency index, $\lambda_{\max }$ is the maximum eigenvalue of the $\mathrm{PCM}$ and $n$ is the number of rows in the matrix. $C R$ can be determined by:

$$
C R=\frac{C I}{R I}
$$

Saaty provides the calculated RI values for matrices of different sizes as shown in Table 3.

Table 3. Consistency indices for a randomly generated matrix

\begin{tabular}{|c|c|c|c|c|c|c|c|c|}
\hline $\mathrm{N}$ & 2 & 3 & 4 & 5 & 6 & 7 & 8 & 9 \\
\hline $\mathrm{RI}$ & 0 & 0.58 & 0.9 & 1.12 & 1.24 & 1.32 & 1.41 & 1.45 \\
\hline
\end{tabular}

where RI is the random consistency index. The threshold was also determined by Saaty, if CR is below 0,1, the PCM can be considered as acceptable from inconsistency point of view. Since the recent research involved several evaluators, the most accepted aggregation process of AHP has been applied: the geometric mean [13] of the respective evaluator scores for creating aggregated matrices of these values..

If " $\mathrm{h}$ " evaluators exist in the procedure

$$
f\left(x_{1}, x_{2}, \ldots, x_{h}\right)=\sqrt[h]{\prod_{k=1}^{h} x_{k}}
$$

Having gained the aggregated matrices, deriving weight vector scores is the next step in the procedure. As consistency has been acceptable, the eigenvector method can be applied as:

$$
w_{A_{i}}=\frac{w_{j}}{w} \frac{w_{i j}}{\sum_{k=1}^{n} w_{i k}}=\left(\frac{w_{j}}{w} \frac{1}{\sum_{k=1}^{n} w_{i k}}\right) w_{i j}
$$

where $j=1, \ldots, m$ and $w=\sum_{i=1}^{m} w_{j}$;

$w j>0(j=1, \ldots, m)$ represents the related weight coordinate from the previous level; $w_{i j}>0(i=1, \ldots, n)$ is the eigenvector computed from the matrix in the current level, $w_{A i}(i=1, \ldots, n)$ is the calculated weight score of current level's elements. Sensitivity analysis enables in understanding the effects of changes in the main criteria on the sub criteria ranking and help decision maker to check the robustness throughout the process.

Spearman is a nonparametric correlation estimators and it used widely in the applied sciences, in order to compare the differences and similarities between different sets [14].

where, $-1 \leq r \leq 1$.

$$
r=\frac{6 \sum D^{2}}{n\left(n^{2}-1\right)}
$$

$D$ is the differences between the ranks of two variables $n$ is the number of samples

A perfect positive correlation is +1 and a perfect negative correlation is -1 , however 0 indicate to no correlation between ranked sets. 


\section{RESULTS}

The aim of this paper is evaluating the situation of Mersin's public transport. The two different groups of participants have made the results of study comparable. The dynamical questionnaire survey has been constructed based on the hierarchical model, 100 evaluators ( 2 managers 'in the relevant field' +18 government officials 'in the relevant field' +80 public passengers) were asked out of the total population of 1.773.852. The number of participants evidently not statically representative however the MCDM provides a deeper insight based on pairwise comparisons than simple statistical survey. The survey was made in July and September 2017, and analyzed in March 2018. Public and transport system planners were asked. Figure 2. Shows criteria weight scores for public side, figure 3. Shows criteria weight scores for planners side.

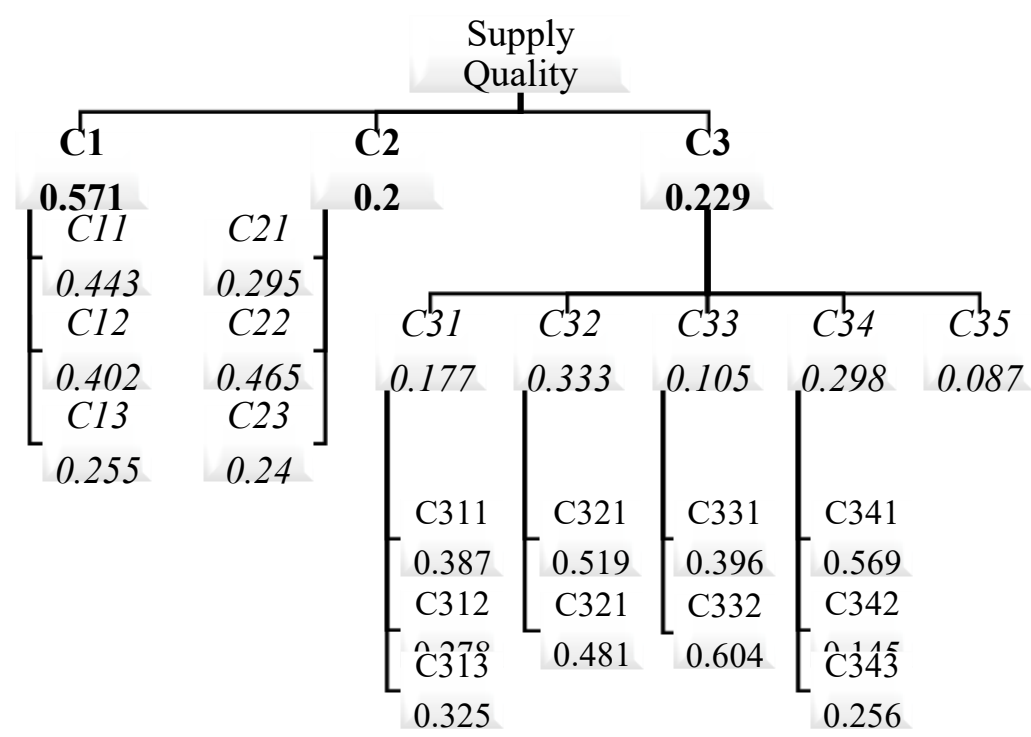

Figure 2. Score results of the public evaluator group 


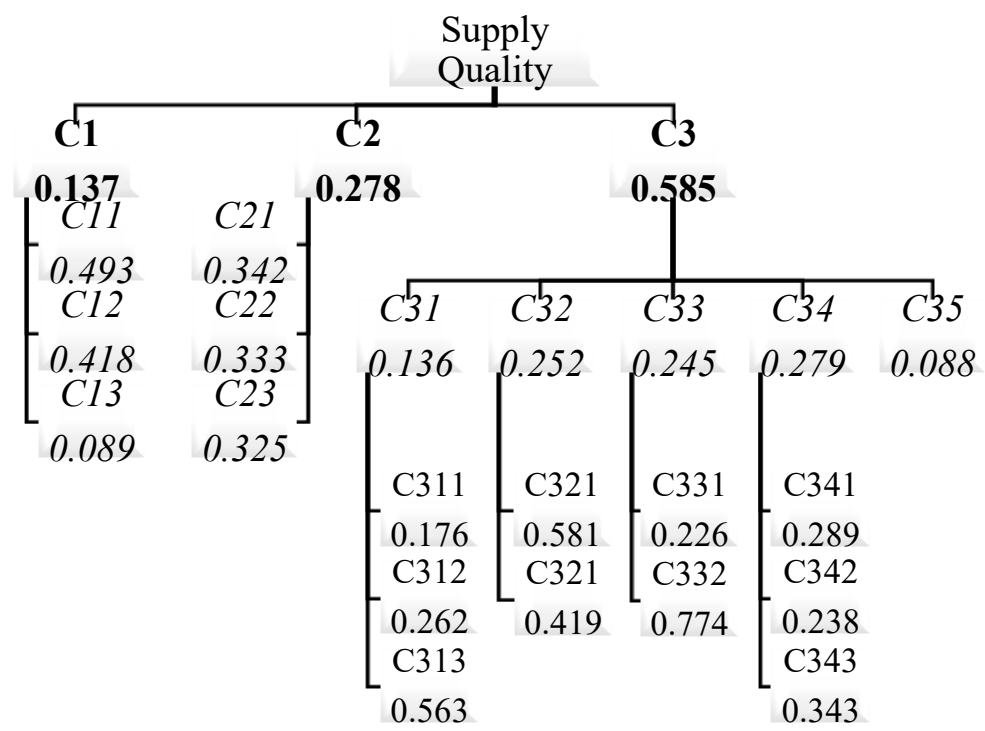

Figure 3. Score results of the planner evaluator groups

In the first level "service quality" was the most important issue for public side followed by "transport quality" and "tractability" however, for planners side the most critical issue was "tractability" followed by "transport quality" and "service quality".

Table 4. Final scores by evaluator groups for Level 1

\begin{tabular}{cccccc}
\hline \multicolumn{3}{c}{ For public side } & \multicolumn{3}{c}{ For planners side } \\
\hline Rank & Criteria & Score & Rank & Criteria & Score \\
\hline 1 & C1 & 0.571 & 1 & C3 & 0.585 \\
2 & C3 & 0.229 & 2 & C2 & 0.278 \\
3 & C2 & 0.2 & 3 & C1 & 0.137 \\
\hline
\end{tabular}

In the second level, the most important issue for public side was "directness", followed by "speed" and "information before travel", however, "Physical comfort" was the most important criteria to develop for planners side, followed by "physical comfort" and "safety of travel". The third level shows the same disagreement between different groups, where "Journey time" was the most important issue for public side followed by "need for transfer" and "fit connection" however, planners concentrate on "limited time of use" as the most important issue to improve it, followed by "need of transfer" and "journey time".

Table 5. Final scores by evaluator groups for Level 2

\begin{tabular}{cccccc}
\hline \multicolumn{3}{c}{ For public side } & & \multicolumn{3}{c}{ For planners side } \\
\hline Rank & Criteria & Score & Rank & Criteria & Score \\
\hline
\end{tabular}




\begin{tabular}{cccccc}
\hline 1 & C32 & 0.19 & 1 & C11 & 0.199 \\
2 & C34 & 0.169 & 2 & C12 & 0.194 \\
3 & C22 & 0.107 & 3 & C13 & 0.189 \\
4 & C31 & 0.101 & 4 & C21 & 0.148 \\
5 & C21 & 0.089 & 5 & C22 & 0.116 \\
6 & C11 & 0.068 & 6 & C34 & 0.039 \\
7 & C22 & 0.062 & 7 & C32 & 0.036 \\
8 & C33 & 0.059 & 8 & C33 & 0.035 \\
9 & C13 & 0.055 & 9 & C23 & 0.024 \\
10 & C23 & 0.051 & 10 & C35 & 0.015 \\
11 & C35 & 0.049 & 11 & C31 & 0.005 \\
\hline
\end{tabular}

Table 6. Final scores by evaluator groups for Level 3

\begin{tabular}{cccccc}
\hline & For public side & \multicolumn{3}{c}{ For planners side } \\
\hline Rank & Criteria & Score & Rank & Criteria & Score \\
\hline 1 & C341 & 0.101 & 1 & C332 & 0.175 \\
2 & C321 & 0.098 & 2 & C321 & 0.021 \\
3 & C322 & 0.091 & 3 & C341 & 0.016 \\
4 & C332 & 0.056 & 4 & C322 & 0.015 \\
5 & C343 & 0.044 & 5 & C343 & 0.013 \\
6 & C311 & 0.039 & 6 & C342 & 0.009 \\
7 & C313 & 0.033 & 7 & C331 & 0.008 \\
8 & C312 & 0.029 & 8 & C313 & 0.002 \\
9 & C342 & 0.025 & 9 & C312 & 0.001 \\
10 & C331 & 0.024 & 10 & C311 & 0.0007 \\
\hline
\end{tabular}

The differences between public and planners evaluator groups are conspicuous however, Spearman correlation has been applied to detect the disagreement degree. However it shows the significance of the collected data.

Table 7. Spearman's rank correlation coefficient results for level 2.

\begin{tabular}{ccccc}
\hline Criteria & $\begin{array}{c}\text { Rank of } \\
\text { Public side }\end{array}$ & $\begin{array}{c}\text { Rank of Planners } \\
\text { side }\end{array}$ & $D$ & $D^{2}$ \\
\hline C31 & 4 & 11 & -7 & 49 \\
C32 & 1 & 7 & -6 & 36 \\
C33 & 8 & 8 & 0 & 0 \\
C34 & 2 & 6 & -4 & 16 \\
C35 & 11 & 10 & 1 & 1 \\
C11 & 5 & 4 & 1 & 1 \\
C12 & 7 & 5 & 2 & 4 \\
C13 & 10 & 9 & 1 & 1 \\
C21 & 6 & 1 & 5 & 25 \\
C22 & 3 & 2 & 1 & 1 \\
C23 & 9 & 3 & 6 & 36 \\
\hline \multicolumn{5}{c}{$r=0.22$} \\
\hline
\end{tabular}


In Level 2 a positive correlation has been detected, the $r$ value of 0.22 refer to weak positive relationship.

Table 8. Spearman's rank correlation coefficient results for level 3.

\begin{tabular}{ccccc}
\hline Criteria & $\begin{array}{c}\text { Rank of } \\
\text { Public side }\end{array}$ & $\begin{array}{c}\text { Rank of } \\
\text { Planners side }\end{array}$ & $D$ & $D^{2}$ \\
\hline C311 & 6 & 10 & -4 & 16 \\
C312 & 8 & 9 & -1 & 1 \\
C313 & 7 & 8 & -1 & 1 \\
C321 & 2 & 2 & 0 & 0 \\
C322 & 3 & 4 & -1 & 1 \\
C331 & 10 & 7 & 3 & 9 \\
C332 & 4 & 1 & 3 & 9 \\
C341 & 1 & 3 & -2 & 4 \\
C342 & 9 & 6 & 3 & 9 \\
C343 & 5 & 5 & 0 & 0 \\
\hline & $n=10$ & \multicolumn{5}{r}{$r=0.7$} \\
\hline
\end{tabular}

In Level 3 a positive correlation has been detected the $r$ value of 0.7 suggests a strong positive relationship.

\section{CONCLUSION}

The main objective of the research was to evaluate public bus transport supply quality factors in Mersin city by applying AHP approach and detect the differences between public and planner evaluator groups by applying Spearman's rank correlation coefficient. The data has been collected on a questionnaire survey conducted by the public and transport system planners in Mersin in 2017. A combined AHP-Spearman model has been suggested in this research because of their numerous advantages over more traditional statistic models. The illustrate a well-understanding and powerful information in order to help the decision makers in their future strategy plans and developments. The outcomes indicate to the real demand of enhancing the most important criteria regarding to the public and planners point of view. AHP approach based on the dynamic analysis and sensitivity analysis supports and gives decision makers the confidence of the consistency and the robustness however, sensitivity analysis showed our stability ranking of factors. Planners and decision makers in Mersin city have to share public point of view in their future transportation project strategic plans. Applying a three-level-hierarchy, the preference order of the issues will probably be very sensitive to the calculated weight scores of the respective previous level. Spearman's rank correlation coefficient results indicate that there is evidence to suggest weak positive relationship for level 2 and a strong positive relationship for level 3. In future studies it is recommended to separate between passengers, non-passengers, planner users and non-users to get the more efficient results. 


\section{REFERENCES}

[1] Buehler, R. and Pucher, J., Making public transport financially sustainable. Transport Policy, 18(1), pp.126-138 (2011).

[2] Duleba, S.; Mishina, T.; Shimazaki, Y. A dynamic analysis on public bus transport's supply quality by using AHP, Transport, Vol. 27, No. 3, pp. 268-275 (2012).

[3] Safe, accountable, flexible, efficient transportation equity act: A legacy for users, US Department of Transportation, Federal Highway Administration, (2005).

[4] Nassereddine M., Eskandari H. An integrated MCDM approach to evaluate public transportation system in Tehran, Transportation Research, Part A, Policy and Practice, Vol. 106, pp. 427-439 (2017).

[5] Mardani A., Zavadskas E. K., Khalifah Z., Jusoh A., Nor K. M. Application of multiple-criteria decision-making techniques and approaches to evaluating of service quality: a systematic review of the literature, Journal of Business Economics and Management, Vol. 16, No. 5, pp. 1034-1068 (2015).

[6] Nosal, K. and Solecka, K., Application of AHP method for multicriteria evaluation of variants of the integration of urban public transport. Transportation Research Procedia, 3, pp.269-278 (2014).

[7] Soner, O., Celik, E. and Akyuz, E., Application of AHP and VIKOR methods under interval type 2 fuzzy environment in maritime transportation. Ocean Engineering, 129, pp.107-116 (2017).

[8] Güner, S., Measuring the quality of public transportation systems and ranking the bus transit routes using multi-criteria decision making techniques. Case Studies on Transport Policy (2018).

[9] Saaty T. L. A scaling method for priorities in hierarchical structures, Journal of Mathematical Psychology, Vol. 15, No. 3, pp. 234-281 (1977).

[10] Saaty, T.L., How to make a decision: the analytic hierarchy process. Interfaces, 24(6), pp.19-43 (1994).

[11] Saaty, T.L., Axiomatic foundation of the analytic hierarchy process. Management science, 32(7), pp.841-855 (1986).

[12] Harker, P.T. and Vargas, L.G., The theory of ratio scale estimation: Saaty's analytic hierarchy process. Management science, 33(11), pp.1383-1403 (1987).

[13] Escobar, M.T., Aguarón, J. and Moreno-Jiménez, J.M., A note on AHP group consistency for the row geometric mean priorization procedure. European Journal of Operational Research, 153(2), pp.318-322 (2004).

[14] Bonett, D.G. and Wright, T.A., Sample size requirements for estimating Pearson, Kendall and Spearman correlations. Psychometrika, 65(1), pp.23-28 (2000).

Budapest University of Technology and Economics, Department of Transport Technology and Economics, Faculty of Transportation and Vehicle Engineering, 1111, Budapest, Hungary,

moslem.sarbast@mail.bme.hu

duleba.szabolcs@mail.bme.hu 